\title{
Impact of headache on sickness absence and utilisation of medical services: a Danish population study
}

\author{
Birthe Krogh Rasmussen, Rigmor Jensen, Jes Olesen
}

\begin{abstract}
Study objective-The aim was to study the extent and type of health service utilisation, medication habits, and sickness absence due to the primary headaches.

Design-This was a cross sectional epidemiological survey of headache disorders in a general population. Headache was diagnosed according to a structured interview and a neurological examination using the criteria of the International Headache Society.
\end{abstract}

Setting-A random sample of 25-64 yearold individuals was drawn from the Danish National Central Person Registry. All subjects were living in the Copenhagen County.

Participants -740 subjects participated (76\% of the sample); 119 had migraine and 578 had tension type headache.

Main results-Among subjects with migraine $56 \%$ had, at some time, consulted their general practitioner because of the migraine. The corresponding percentage among subjects with tension type headache was 16. One or more specialists had been consulted by $16 \%$ of migraine sufferers and by $4 \%$ of subjects with tension type headache. The consultation rates of chiropractors and physiotherapists were $5-8 \%$. Hospital admissions and supplementary laboratory investigations due to headache were rare $(<3 \%)$. Half of the migraine sufferers and $83 \%$ of subjects with tension type headache in the previous year had managed with at least one type of drug in the current year. Acetylsalicylic acid preparations and paracetamol were the most commonly used analgesics. Prophylaxis of migraine was used by $7 \%$. In the preceeding year $43 \%$ of employed migraine sufferers and $12 \%$ of employed subjects with tension type headache had missed one or more days of work because of headache. Most common was 1-7 days off work. The total loss of workdays per year due to migraine in the general population was estimated at 270 days per 1000 persons. For tension type headache the corresponding figure was 820 . Women were more likely to consult a practitioner than men, whereas no significant sex difference emerged as regards absenteeism from work.

Conclusions - The impact of the headache disorders on work performance in the general population is substantial, and the disorders merit increased attention. f Epidemiol Community Health 1992; 46: 443-446
In a random population of 25-64 year old men and women, we recently reported the lifetime prevalence of migraine to be $16 \%$ and of tension type headache, $78 \%{ }^{1}$ In the migraine group nearly all stated that the pain impaired or abolished working capacity or other activities, and in the group with tension type headache about $60 \%$ stated so.

Little is known about the extent and type of health service utilisation and the work consequences resulting from these disorders. The purpose of this paper is to analyse these factors in a general Danish population. Some aspects of the organisation and financing of the Danish health system must be described for our results to be interpreted.

Hospitals in Denmark are owned and run by the counties. They are financed from taxation. The services include, inter alia, hospital admissions, casualty ward services, and the specialist treatment of outpatients. The majority of medical specialists are employed by the hospitals.

General practice, full time specialist practice, and adult dental practice are semi-private. As a rule, services rendered by general practitioners, doctors on medical home visit, private specialists, physiotherapists, and chiropractors are paid for through the Danish National Health Insurance, which is financed by taxation. Services rendered by home nurses and visiting paediatric nurses, as well as the school dental service, are run by the municipalities and financed via the municipal taxes.

As a family doctor, the general practitioner plays a key role in the Danish health service, being the first link in the chain of services rendered by the health system. Hospital admission and access to private specialist services require referral by the general practitioner.

In 1989 in the Copenhagen County, the general practitioner/population ratio was approximately $1 / 1600$, the full time private specialist/population ratio approximately $1 / 5200$, and the dentist/ population ratio approximately $1 / 1700$. The general practioner ratio corresponds to the average for the whole of Denmark, while the latter two ratios are higher. The 600000 inhabitants of the district are served by three fully specialised hospitals with approximately 800 beds each.

\section{Methods}

SUBJECTS AND INVITATION

The study population and the methods used have been described in detail elsewhere. ${ }^{1}$ In summary, the participation rate was $76 \%$ and the examined population comprises 740 randomly selected 25-64 year old persons, 387 men and 353 women, living in the western part of Copenhagen County. 
All subjects were invited for a general health survey with focus on headache disorders. The subjects were informed that all information was to be used for research purposes only and regarded as strictly confidential. The project was approved by the ethics committee for Copenhagen County and by the Inspection of Registry.

\section{THE EXAMINATION}

The study took place at the Copenhagen County Hospital in Glostrup between January and July 1989. The survey included a self administered questionnaire concerning sociodemographic variables, a structured headache interview, a general physical examination, and a neurological examination. The interview included an extensive description of the headache history including the headache frequency, duration, location, character of pain, intensity, accompanying symptoms, precipitating factors, onset of headache, familial occurrence, influence on working ability, and utilisation of health services and medicine. The exact wording and details of the replies to individual questions about various features of migraine and tension type headache have been published previously. ${ }^{1}$ Based on the information from the standardised headache interview, all headache disorders were classified according to the operational diagnostic criteria of the International Headache Society (IHS). ${ }^{2}$ In this classfication system subjects receive a diagnosis for each distinct headache form experienced. Thus subjects with, eg, both migraine and tension type headache are included in the diagnostic group of migraine as well as that of tension type headache. Data concerning each specific headache type within the same subject were recorded.

Among the participants, 709 subjects had at any time experienced at least one type of headache (including primary as well as secondary headaches), 119 subjects had at any time had migraine, and 578 subjects had had tension type headache. In the previous year, 77 subjects had had migraine and 549 had had tension type headache.

Work absence due to migraine and tension type headache during the 12 months prior to the examination was analysed among those participants who had paid work or were students at the time of examination, ie, among 618 subjects (of these, 67 subjects had migraine and 472 had tension type headache in the previous year).

\section{STATISTICAL METHODS}

The $\chi^{2}$ test was applied to the data, with a five per cent level of significance.

Table I Participants with migraine or tension type headache at any time who reported having consulted their general practitioner, a specialist, a hospital, or other category of therapist at some time because of headaches. Values are percentages

\begin{tabular}{|c|c|c|c|c|c|c|}
\hline & \multicolumn{3}{|l|}{ Migraine } & \multicolumn{3}{|c|}{ Tension type } \\
\hline & $\begin{array}{l}M e n \\
(n=30)\end{array}$ & $\begin{array}{l}\text { Women } \\
(n=89)\end{array}$ & $\begin{array}{l}\text { All } \\
(n=119)\end{array}$ & $\begin{array}{l}\text { Men } \\
(n=266)\end{array}$ & $\begin{array}{l}\text { Women } \\
(n=312)\end{array}$ & $\begin{array}{l}\text { All } \\
(n=578)\end{array}$ \\
\hline $\begin{array}{l}\text { General practitioner } \\
\text { Specialist } \\
\text { Hospital } \\
\text { Chiropractor } \\
\text { Physiotherapist } \\
\text { Herbalist } \\
\text { Other }\end{array}$ & $\begin{array}{r}43 \\
17 \\
3 \\
3 \\
0 \\
3 \\
3\end{array}$ & $\begin{array}{r}61 \\
16 \\
3 \\
8 \\
11 \\
1 \\
7\end{array}$ & $\begin{array}{r}56 \\
16 \\
3 \\
7 \\
8 \\
2 \\
6\end{array}$ & $\begin{array}{r}10 \\
4 \\
2 \\
2 \\
4 \\
<1 \\
1\end{array}$ & $\begin{array}{c}22 \ddagger \\
3 \\
1 \\
8 \dagger \\
11^{\star} \\
1 \\
2\end{array}$ & $\begin{array}{r}16 \\
4 \\
1 \\
5 \\
8 \\
1 \\
1\end{array}$ \\
\hline
\end{tabular}

Sex difference: ${ }^{\star} p<0.01, \dagger p<0.001, \neq p<0.0001$

\section{Results}

PHYSICIANS, PHYSIOTHERAPISTS, AND OTHERS CONSULTED

Among migraine sufferers $56 \%$ had consulted their general practitioner at some time because of migraine. Among subjects with tension type headache $16 \%$ had consulted their general practitioner at some time because of tension type headache (table I). The consultation rate was higher among women than among men. In both migraine sufferers and subjects with tension type headache the consultation of a general practitioner was positively correlated to the frequency of attacks (migraine: $\mathrm{p}<0.05$; tension type headache: $p<0.00001$ ). Among migraine sufferers $16 \%$ had consulted a specialist; among subjects with tension type headache only $4 \%$ had consulted a specialist. No significant differences emerged between subjects with migraine and tension type headache in the consultation rates at hospital, chiropractor, physiotherapist, or herbalist. Women with tension type headache were significantly more likely to contact chiropractors and physiotherapists than men (table I).

Among subjects with both migraine and tension type headache, $58 \%$ had consulted a general practitioner because of migraine and $33 \%$ because of tension type headache. These consultation rates were higher than those in subjects with pure migraine or pure tension type headache, but only to a significant degree with regard to tension type headache $(\mathrm{p}<0.00001)$.

HOSPITAL ADMISSIONS AND DIAGNOSTIC TESTS Sixteen participants said they had been admitted to hospital because of headache. This corresponds to $2 \%(16 / 740)$ of the total population. Supplementary diagnostic investigations due to headache were rare $(<3 \%)$ and no significant sex differences were found (table II).

Table II Laboratory investigations for headache among participants who had ever had any form of headache. Values are percentages

\begin{tabular}{llcc}
\hline & $\begin{array}{l}\text { Men } \\
(n=361)\end{array}$ & $\begin{array}{l}\text { Women } \\
(n=348)\end{array}$ & $\begin{array}{l}\text { All } \\
(n=709)\end{array}$ \\
\hline Hospital admission & 3 & 1 & 2 \\
EEG & 2 & 3 & 2 \\
CT scanning & 2 & 1 & 2 \\
Cranial $x$ ray & 2 & 2 & 2 \\
$X$ ray of cervical spine & 1 & 3 & 2 \\
Cranial scintigraphy & 0 & $<1$ & $<1$ \\
Other & 0 & $<1$ & $<1$
\end{tabular}

\section{MEDICATION}

Among subjects with migraine in the previous year, $49 \%(38 / 77)$ stated that they had used medicine for the migraine in the current year: $35 \%(8 / 23)$ of men and $56 \%(30 / 54)$ of women, there being no significant sex difference. Correspondingly, $87 \%(480 / 549)$ of the subjects with tension type headache in the previous year had used medicine for the headache in this year: $82 \%$ (201/245) of men and 92\% (279/304) of women, $\mathrm{p}<0.001$. The types and frequency of the medication used in the previous year are given in table III. Acetylsalicylic acid preparations (including mixed analgesics with codeine or caffeine) were used by $31 \%$ of migraine sufferers and by $59 \%$ with tension type headache. It was most common to use these preparations one to three times a 
month. Paracetamol was used by $14 \%$ with migraine and by $42 \%$ with tension type headache. There was a significant positive correlation between frequencies of migraine and tension type headache and the frequency of analgesic drug intake.

Ergotamine or dihydroergotamine preparations were used by $17 \%$ of migraine sufferers on one to three occasions per month. Prophylactic treatment with $\beta$ blockers or clonidine was used by $4 \%$ and $3 \%$ of the subjects with migraine in the previous year respectively. None used calcium antagonists, pizotifen, or cyproheptadine. Overall, $7 \%$ received prophylactic treatment. Those subjects receiving prophylactic treatment all stated that they had less than 15 migraine days a year during treatment. Among subjects with tension type headache in the previous year the most frequent medications used were acetylsalicylic acid preparations and paracetamol. Benzodiazepines, neuroleptics, and antidepressants were rarely used.

\section{WORK ABSENCE}

Of gainfully employed participants with migraine in the previous year, $43 \%(29 / 67)$ said they had been absent from work at least once during the year because of migraine (table IV), corresponding to $5 \%(29 / 618)$ of the total working sample. Among those with days off because of migraine, $91 \%$ were absent for less than seven days, and $9 \%$ up to 14 days a year.

Table III Medication in the previous year used by subjects to treat migraine (M) $(n=77)$ and tension type headache $(T H)(n=549)$. Values are percentages

\begin{tabular}{|c|c|c|c|c|c|}
\hline & & \multicolumn{4}{|c|}{ Frequency of use of medicine } \\
\hline & & $\begin{array}{l}1-3 \text { times } \\
\text { a month }\end{array}$ & $\begin{array}{l}\text { 1-3 times } \\
\text { a week }\end{array}$ & Daily & Total \\
\hline Acetylsalicylic acid preparations & SH & $\begin{array}{l}27 \\
45\end{array}$ & $\begin{array}{r}3 \\
11\end{array}$ & $\begin{array}{l}1 \\
4\end{array}$ & $\begin{array}{l}31 \\
59\end{array}$ \\
\hline Paracetamol & $\begin{array}{l}\mathbf{M} \\
\mathrm{TH}\end{array}$ & $\begin{array}{r}9 \\
28\end{array}$ & $\begin{array}{r}1 \\
10\end{array}$ & $\begin{array}{l}4 \\
4\end{array}$ & $\begin{array}{l}14 \\
42\end{array}$ \\
\hline Dextropropoxifen & $\begin{array}{l}\text { M } \\
\text { TH }\end{array}$ & $\begin{array}{r}0 \\
<1\end{array}$ & $\begin{array}{r}0 \\
<1\end{array}$ & $\begin{array}{r}0 \\
<1\end{array}$ & $\begin{array}{l}0 \\
1\end{array}$ \\
\hline $\begin{array}{l}\text { Non-steroidal anti-inflammatory } \\
\text { drugs }\end{array}$ & $\begin{array}{l}\text { y } \\
\text { TH }\end{array}$ & $\begin{array}{l}4 \\
1\end{array}$ & $\begin{array}{r}0 \\
<1\end{array}$ & $\begin{array}{l}\mathbf{0} \\
\mathbf{0}\end{array}$ & $\begin{array}{l}7 \\
2\end{array}$ \\
\hline Ergotamine/dihydroergotamine & $\begin{array}{l}\text { M } \\
\text { TH }\end{array}$ & $\begin{array}{r}17 \\
0\end{array}$ & $\begin{array}{l}0 \\
0\end{array}$ & $\begin{array}{l}0 \\
0\end{array}$ & $\begin{array}{r}17 \\
0\end{array}$ \\
\hline Methysergide & $\begin{array}{l}\text { M } \\
\text { TH }\end{array}$ & $\begin{array}{l}0 \\
0\end{array}$ & $\begin{array}{r}0 \\
<1\end{array}$ & $\begin{array}{l}0 \\
0\end{array}$ & $\begin{array}{r}0 \\
<1\end{array}$ \\
\hline Clonidine & $\begin{array}{l}\text { M } \\
\text { TH }\end{array}$ & $\begin{array}{l}1 \\
0\end{array}$ & $\begin{array}{l}0 \\
0\end{array}$ & $\begin{array}{l}3 \\
0\end{array}$ & $\begin{array}{l}4 \\
0\end{array}$ \\
\hline$\beta$ Blockers & $\stackrel{\text { MH }}{\text { TH }}$ & $\begin{array}{l}0 \\
0\end{array}$ & $\begin{array}{l}0 \\
0\end{array}$ & $\begin{array}{l}4 \\
0\end{array}$ & $\begin{array}{l}4 \\
0\end{array}$ \\
\hline Narcotic analgesics & $\stackrel{\text { MH }}{\text { TH }}$ & $\begin{array}{l}1 \\
0\end{array}$ & $\begin{array}{l}1 \\
0\end{array}$ & $\begin{array}{l}0 \\
0\end{array}$ & $\begin{array}{l}3 \\
0\end{array}$ \\
\hline Benzodiazepines & $\begin{array}{l}\text { M } \\
\text { TH }\end{array}$ & $\begin{array}{r}3 \\
<1\end{array}$ & $\begin{array}{l}0 \\
0\end{array}$ & $\begin{array}{l}0 \\
0\end{array}$ & $\begin{array}{r}3 \\
<1\end{array}$ \\
\hline Neuroleptics & $\begin{array}{l}\text { M } \\
\text { TH }\end{array}$ & $\begin{array}{l}0 \\
0\end{array}$ & $\begin{array}{l}1 \\
0\end{array}$ & $\begin{array}{l}0 \\
0\end{array}$ & $\begin{array}{l}1 \\
0\end{array}$ \\
\hline Antidepressants & $\begin{array}{l}\text { M } \\
\text { TH }\end{array}$ & $\begin{array}{l}0 \\
0\end{array}$ & $\begin{array}{l}0 \\
0\end{array}$ & $\begin{array}{r}0 \\
<1\end{array}$ & $\begin{array}{r}0 \\
<1\end{array}$ \\
\hline $\begin{array}{l}\text { Others (vitamins, minerals, } \\
\text { naturopaths, others) }\end{array}$ & $\begin{array}{l}\text { M } \\
\text { TH }\end{array}$ & $\begin{array}{r}4 \\
<1\end{array}$ & $\begin{array}{l}0 \\
0\end{array}$ & $\begin{array}{l}1 \\
1\end{array}$ & $\begin{array}{l}8 \\
2\end{array}$ \\
\hline
\end{tabular}

Table IV Absence rate and the number of days off work in the previous year because of migraine or tension type headache among gainfully employed participants with migraine or tension type headache in the previous year. Values are percentages

\begin{tabular}{|c|c|c|c|c|c|c|}
\hline & \multicolumn{3}{|l|}{ Migraine } & \multicolumn{3}{|c|}{ Tension type } \\
\hline & $\begin{array}{l}\text { Men } \\
(n=22)\end{array}$ & $\begin{array}{l}\text { Women } \\
(n=45)\end{array}$ & $\begin{array}{l}A l l \\
(n=67)\end{array}$ & $\begin{array}{l}\text { Men } \\
(n=215)\end{array}$ & $\begin{array}{l}\text { Women } \\
(n=257)\end{array}$ & $\begin{array}{l}\text { All } \\
(n=472)\end{array}$ \\
\hline Absence rate & 32 & 49 & 43 & 9 & 14 & 12 \\
\hline $\begin{array}{l}\text { Days off work } \\
0 \\
1-7 \\
8-14 \\
>14\end{array}$ & $\begin{array}{r}68 \\
27 \\
5 \\
0\end{array}$ & $\begin{array}{r}51 \\
44 \\
4 \\
0\end{array}$ & $\begin{array}{r}57 \\
39 \\
5 \\
0\end{array}$ & $\begin{array}{r}91 \\
6 \\
3 \\
<1\end{array}$ & $\begin{array}{r}86 \\
7 \\
4 \\
3\end{array}$ & $\begin{array}{r}88 \\
8 \\
3 \\
2\end{array}$ \\
\hline
\end{tabular}

The absence rate because of tension type headache in the previous year among sufferers who were gainfully employed was $12 \%(56 / 472)$, and of these $16 \%$ were absent for more than 14 days (table IV). The most common length of absence in this group was 15-30 days, but two women with tension type headache had very long periods of sick leave $(>180$ days). The absence rate due to tension type headache in the total population was $9 \%(56 / 618)$. Regarding both migraine and tension type headache, women had higher absence rates than men, but the sex difference was not significant. Overall, the absence rate among migraine sufferers was significantly higher than in subjects with tension type headache $(p<0.00001)$.

Among subjects suffering from both migraine and tension type headache in the previous year, $46 \%$ had been absent due to migraine and $20 \%$ due to tension type headache. Compared to subjects with pure migraine or tension type headache the absence rates in subjects with coexisting migraine and tension type headache were somewhat higher, although only significantly so in tension type headache $(p<0.05)$.

\section{Discussion}

MEDICAL SERVICES

Nearly half of the subjects with migraine and more than four fifths of the subjects with tension type headache had never contacted their general practitioner because of the headache. This consultation rate is in agreement with previous European reports, ${ }^{3-5}$ but may be somewhat different from that in other areas due to varying cultural and social backgrounds and even to variations in the availability of general practitioners. The higher rates in women are in agreement with most previous studies, ${ }^{5-8}$ though equal consultation rates in men and women were reported in one study. ${ }^{9}$ The percentage of subjects who had consulted a specialist or a hospital is in accordance with previous reports. ${ }^{310}$ The frequency of contacts with a chiropractor or physiotherapist was somewhat higher than that reported in a study in the United States, ${ }^{7}$ but again regional variations in the health service systems and in the level of medical care, as well as different traditions, may influence the findings. The higher consultation rates in subjects with coexisting migraine and tension type headaches compared to subjects with pure migraine and pure tension type headache are in concordance with Berkson's view that subjects with more than one disease are more likely to seek medical care than subjects with only one disease. ${ }^{11}$

Supplementary investigation was rarely resorted to. Thus Danish diagnostic tradition is in agreement with the IHS criteria which reserve laboratory investigations such as computerised tomography for exceptional cases. The laboratory investigations are mainly used to exclude organic causative factors in subjects where history and physical and/or neurological examinations could suggest the presence of a symptomatic headache. The use of laboratory investigation of headache has not been assessed in any previous population based study.

Our present knowledge of the medication habits of headache sufferers is scant and mainly based on headache prone populations. The 
present study of headache in an unselected population provides an undistorted view of this aspect, including subjects who manage with no, small, or moderate amounts of medication for their headaches. Thus half the subjects with migraine and $13 \%$ of the subjects with tension type headache in the previous year managed entirely without medicine during this year. About one quarter of migraine sufferers and one third of subjects with tension type headache used one or more forms of medicine one to three times a month. The most commonly used analgesics were acetylsalicylic acid preparations and paracetamol, ie, the same as reported in other studies. ${ }^{67912}$ They are in general the two most popular prescription free drugs in Denmark. Drug consumer surveys show that women take more analgesics than men. ${ }^{13-15}$ However, we found significant sex differences with regard to the use of medicine only in tension type headache and not in migraine. The higher rates of use among women in consumer surveys can probably partly be explained by the higher prevalence of headache disorders in women.

We have recently reported that $14 \%$ of subjects with migraine had attacks on more than 14 days a year, ${ }^{1}$ and in addition $7 \%$ received prophylactic treatment on which they had less than 15 migraine days per year. Assuming that these drugs were correctly prescribed, ie, given only to sufferers with two or more migraine days a month, about $21 \%$ of subjects with migraine in the previous year would have had frequent migraine attacks if untreated.

\section{WORK CONSEQUENCES}

Subjects were asked to give a retrospective estimate of work days missed in the preceding year due to migraine and/or tension type headache. It is probably fair to assume that the numbers obtained by this method are more likely to have been underestimated than overestimated, mainly because of forgetfulness. On the other hand, it may be expected that social complications or other less acceptable causes of sick leave occurring in conjunction with headache may lead to sickness certification for headache even when headache was not the main reason.

The extent of work absence due to migraine found in the present study is higher than reported from northern Finland, ${ }^{16}$ but similar to Waters' result in the Pontypridd survey as regards subjects with headache and three features of migraine. ${ }^{8}$ The absence rate and the number of days off work due to tension type headache are quite similar to those reported in Finland. ${ }^{16}$ Most other studies dealing with sickness absence have not, however, analysed migraine and tension type headache separately. Thus Clarke and Waters reported in a study of a London general practice that $8 \%$ of men with headache missed work in the year before the survey. ${ }^{17}$ In a similar analysis, Newland $e t \mathrm{al}^{5}$ reported that a figure of about $6 \%$ and that the number of days lost increased directly in parallel with the number of features of migraine present. Benassi et al found an absence rate of $15 \%$ among working subjects with headache in the preceding year ${ }^{10}$ and Linet et al reported an absence rate due to the most recent headache of about $12 \%{ }^{7}$ Regional variations-including the social security systems-and methodological variations (definition of migraine and tension type headache, methods of data collection, the population studied, etc) must be considered when comparing the present results regarding work consequences with other studies.

In the present study, the absence rate due to migraine was significantly higher than that due to tension type headache. In the total population, however, the absence rate from migraine was $5 \%$ and from tension type headache $9 \%$. Thus, when considering the socioeconomic impact of the headache disorders, tension type headaches are of greater importance simply because of the larger population at risk of such headaches.

The present data, based on a representative sample of the general population, allow us to give a rough estimate of the number of days lost from work in the preceding year attributable to migraine or tension type headache. On average $4 \%$ of the total employed population between the ages of 25 and 64 years were absent from work because of migraine for about four days a year and $1 \%$ for 11 days, corresponding to a total of 270 work days lost per 1000 persons in the past year due to migraine. The corresponding calculations with regard to tension type headache are 5\% absent for four days, $2 \%$ for 11 days, and $2 \%$ for 20 days, giving a total of 820 work days lost per 1000 employed persons in a year.

Altogether, the time off work due to the headache disorders is substantial and justifies increased attention to these disorders.

This study received statistical support from The Danish Medical Research Council.

1 Rasmussen BK, Jensen R, Schroll M, Olesen J. Epidemiology of headache in a general population-a prevalence study. $\mathcal{F}$ Clin Epidemiol 1991; 44: 1147-57.

2 Headache Classification Committee of the Internationa headache disorders, cranial neuralgias and facial pain. Cephalalgia 1988; 8 (suppl 7).

3 Ekbom K, Ahlborg B, Schèle R. Prevalence of migraine and cluster headache in Swedish men of 18. Headache 1978; 18 cluster
W-19.
Waters

4 Waters WE, O'Connor PJ. Epidemiology of headache and migraine in women. $\mathcal{F}$ Neurol Neurosurg Psychiatry 1971; 34: $148-53$.

5 Newland CA, Illis LS, Robinson PK, Batchelor BG, Waters WE. A survey of headache in an English City. Res Clin Stud Headache 1978; 5: 1-20.

6 Hollnagel H, Nørrelund $\mathrm{N}$. Headache among 40 year-olds in Glostrup. Ugeskr Laeger 1980; 142: 3071-7.

7 Linet MS, Stewart WF, Celentano DD, Ziegler D, Sprecher Linet MS, Stewart WF, Celentano DD, Ziegler D, Sprecher
M. An epidemiologic study of headache among adolescents

and young adults. $\mathcal{F} A M A 1989 ; 261: 2211-6$.
8 Water WE. Headache. In: Bourke GJ, ed. Series in clinical Water WE. Headache. In: Bourke GJ, ed. $S$

epidemiology. London: Croom Helm, 1986 .
Nikiforow R., Headache medication habits in Northern Fikiforow R., Headache medication
Finland. Headache 1980; 20: 274-8.

10 Benassi G, D'Alessandro R, Lenzi PL, Manzaroli D, Baldrati A, Lugaresi $E$. The economic burden of headache: an epidemiological study in the Republic of San Marino. Headache 1986; 26: 457-9.

11 Berkson J. Limitations of the application of fourfold table analysis to hospital data. Biometrics Bull 1946; 2: 47-53. 12 Ogden H. Headache studies, statistical data. $\mathcal{F}$ Allergy 1952 23: 58-75.

13 Krasnik A, Launsø L, Ølgod J. Den primare sundhedstjeneste. København: Sundhedsstyrelsen 1982 (in Danish).

14 Rasmussen NK, Groth MV, Bredkjær SR, Madsen M, Kamper-Jorgensen F. Sundhed $\mathbb{E}$ Sygelighed $i$ Danmark. København: Dansk Institut for Klinisk Epidemiologi, 1987 (in Danish).

15 Geckler S, Rasmussen MK, Enevoldsen B, Hansen H, Bredahl D. The distribution of the living conditions. Main results from the Welfare Survey. Part II. The elements of the iving conditions. Copenhagen: The Danish National Institute of Social Research, 1978. (in Danish)

16 Nikiforow R, Hokkanen E. Effects of headache on working ability: a survey of an urban and a rural population in Northern Finland. Headache 1979; 19: 214-8.

17 Waters WE. The epidemiology of migraine. Bracknell: Boehringer Ingelheim, 1974. 